\title{
Structural Correlates of CA2 and CA3 Pyramidal Cell Activity in Freely-Moving Mice
}

\author{
Lingjun Ding, ${ }^{1,2,3}$ Hongbiao Chen, ${ }^{1,2,3}$ Maria Diamantaki, ${ }^{2,3}$ Stefano Coletta, ${ }^{2,3}$ Patricia Preston-Ferrer, ${ }^{1,2}$ \\ and ${ }^{-}$Andrea Burgalossi ${ }^{1,2}$ \\ ${ }^{1}$ Institute of Neurobiology, University of Tübingen, Tübingen 72076, Germany, ${ }^{2}$ Werner-Reichardt Centre for Integrative Neuroscience, Tübingen \\ 72076, Germany, and ${ }^{3}$ Graduate Training Centre of Neuroscience, IMPRS, Tübingen 72074, Germany
}

Plasticity within hippocampal circuits is essential for memory functions. The hippocampal CA2/CA3 region is thought to be able to rapidly store incoming information by plastic modifications of synaptic weights within its recurrent network. Highfrequency spike-bursts are believed to be essential for this process, by serving as triggers for synaptic plasticity. Given the diversity of CA2/CA3 pyramidal neurons, it is currently unknown whether and how burst activity, assessed in vivo during natural behavior, relates to principal cell heterogeneity. To explore this issue, we juxtacellularly recorded the activity of single CA2/CA3 neurons from freely-moving male mice, exploring a familiar environment. In line with previous work, we found that spatial and temporal activity patterns of pyramidal neurons correlated with their topographical position. Morphometric analysis revealed that neurons with a higher proportion of distal dendritic length displayed a higher tendency to fire spikebursts. We propose that the dendritic architecture of pyramidal neurons might determine burst-firing by setting the relative amount of distal excitatory inputs from the entorhinal cortex.

Key words: hippocampus; in vivo electrophysiology; juxtacellular recordings; place cell; pyramidal neurons; spatial navigation

\section{Significance Statement}

High-frequency spike-bursts are thought to serve fundamental computational roles within neural circuits. Within hippocampal circuits, spike-bursts are believed to serve as potent instructive signals, which increase the efficiency of information transfer and induce rapid modifications of synaptic efficacies. In the present study, by juxtacellularly recording and labeling single CA2/CA3 neurons in freely-moving mice, we explored whether and how burst propensity relates to pyramidal cell heterogeneity. We provide evidence that, within the CA2/CA3 region, neurons with higher proportion of distal dendritic length display a higher tendency to fire spike-bursts. Thus, the relative amount of entorhinal inputs, arriving onto the distal dendrites, might determine the burst propensity of individual CA2/CA3 neurons in vivo during natural behavior.

Received Jan. 13, 2020; revised May 3, 2020; accepted May 5, 2020.

Author contributions: L.D., M.D., S.C., and P.P.-F. performed research; L.D., H.C., and P.P.-F. analyzed data; L.D., H.C., P.P.-F., and A.B. edited the paper; A.B. designed research; A.B. wrote the paper.

This work was supported by Eberhard Karls University of Tübingen, Werner Reichardt Center for Integrative Neuroscience (Excellence Cluster funded by the Deutsche Forschungsgemeinschaft within the framework of the Excellence Initiative EXC 307), and Deutsche Forschungsgemeinschaft Grants BU3126/1-1 and BU3126/2-1.

We thank Alexandra Eritja for excellent technical assistance; and the electronics and fine-mechanics workshops (Universitätsklinikum Tübingen) for excellent support.

M. Diamantaki's present address: Institute of Molecular Biology and Biotechnology, Foundation for Research and Technology Hellas, Heraklion, Crete, 700 13, Greece.

S. Coletta's present address: U.A. Whitaker Biomedical Engineering Building, Georgia Tech, 313 Ferst Drive, Atlanta, GA 30332-0535.

The authors declare no competing financial interests.

Correspondence should be addressed to Andrea Burgalossi at andrea.burgalossi@cin.uni-tuebingen.de or Patricia Preston-Ferrer at patricia.preston@cin.uni-tuebingen.de.

https://doi.org/10.1523/JNEUROSCI.0099-20.2020

Copyright $\odot 2020$ the authors

\section{Introduction}

The ability to encode, store, and retrieve episodic experiences critically depends on the hippocampus. The fundamental units of hippocampal representations are place cells, neurons that encode the animal's location in space (O'Keefe and Dostrovsky, 1971; O'Keefe, 1976), as well as other behaviorally relevant stimuli (Eichenbaum, 2017). According to current theories, the individual events of episodic experiences are rapidly associated and stored as unique patterns of hippocampal place cell activities. These rapid associations are thought to be supported by plastic synaptic changes within the CA2/CA3 network, which by means of its strong recurrent collaterals is able to rapidly store (and retrieve) specific patterns of place cell activities (Rolls and Treves, 1994; Knierim and Neunuebel, 2016). Computational and experimental evidence indicates that spike-bursts, trains of action potentials fired in rapid succession $(<6 \mathrm{~ms}$ interspike interval [ISI]), are likely to play a crucial role for the rapid formation (as well as retrieval) of memory engrams (Treves and Rolls, 
1992; Kaifosh and Losonczy, 2016). For example, in the CA1 region, spike-bursts can be evoked by the concomitant activation of proximal and distal inputs (Takahashi and Magee, 2009), thus acting as an associative signal, which can induce plastic changes at the activated synapses. Indeed, the artificial induction of spike-bursts in individual hippocampal pyramidal (Pyr) neurons can rapidly modify place-cell activity (Diamantaki et al., 2018) and induce the emergence of place fields in silent neurons (Bittner et al., 2015, 2017). The importance of spike-bursts on hippocampal coding is also highlighted by the fact that bursty neurons are more likely to be recruited in the engram (Epsztein et al., 2011; Mizuseki et al., 2011; Rich et al., 2014) and that evoking a single spike-burst in individual Pyr neurons was shown to be sufficient for initiating network synchronization (de la Prida et al., 2006; Wittner and Miles, 2007; Marissal et al., 2012). Together, this evidence indicates that spike-bursts can function as potent instructive signals within hippocampal circuits, which are likely to contribute to its associative mnemonic functions.

In order to resolve the cellular mechanisms of spike-burst generation, it is necessary to understand whether and how burst propensity relates to Pyr cell diversity. Hippocampal Pyr neurons have been classically assumed to be a relatively homogeneous population; however, recent work has demonstrated that their structural and functional properties change systematically according to topographical position (Ishizuka et al., 1995; Nakamura et al., 2013; H. Lee et al., 2015; Lu et al., 2015; Oliva et al., 2016; Sun et al., 2017; Fernandez-Lamo et al., 2019; Raus Balind et al., 2019). Specifically, in vivo extracellular work has shown that, on average, the tendency of neurons to fire spikebursts changes gradually along the CA2/CA3 proximodistal axis (Oliva et al., 2016), in line with the graded changes in neuronal morphology, input-output connectivity, intrinsic properties, and molecular expression profiles (Ishizuka et al., 1995; Sun et al., 2017; Fernandez-Lamo et al., 2019). Notably, even within the same topographical level, Pyr neurons are heterogeneous, thus raising the possibility that different neuronal morphologies could show distinct tendencies to fire spike-bursts, as supported by recent work in vitro (Marissal et al., 2012; Raus Balind et al., 2019) and in the anesthetized brain (Hunt et al., 2018). However, whether and how the burst propensity of single neurons, assessed in vivo during natural behavior, relates to morphologic Pyr cell heterogeneity, have remained unresolved.

To bridge this gap, we took advantage of recently optimized juxtacellular recording techniques, adapted to freely-moving mice (Diamantaki et al., 2018), which allowed us to monitor the activity of single CA2 and CA3 neurons while the animals explored a familiar environment. Our data align with previous work and indicate that topographical location is a strong determinant of in vivo Pyr cell activity. We extend these observations by showing that neurons with distinct dendritic architectures display different tendencies to fire spike-bursts. We propose that dendritic architecture might control burst-firing during exploratory behavior by selecting the amount and origin of incoming excitatory inputs.

\section{Materials and Methods}

Juxtacellular recordings. All experimental procedures were performed according to German guidelines on animal welfare under the supervision of local ethics committees.

Experimental procedures for obtaining juxtacellular recordings, signal acquisition and processing, and animal tracking in freely-moving male WT C57BL/6J (>6 weeks old; Charles River) were essentially performed as described previously (Tang et al., 2014a; Diamantaki et al.,
2018). Glass electrodes with resistance 4-6 $\mathrm{m} \Omega$ were filled with $1.5 \%-2 \%$ Neurobiotin (Vector Laboratories) in Ringer's solution containing (in $\mathrm{mm}$ ): $135 \mathrm{NaCl}, 5.4 \mathrm{KCl}, 5 \mathrm{HEPES}, 1.8 \mathrm{CaCl}_{2}$, and $1 \mathrm{MgCl}_{2}$ or Intracellular solution containing the following (in $\mathrm{mm}$ ): $135 \mathrm{~K}$-gluconate, 10 HEPES, $10 \mathrm{Na}_{2}$-phosphocreatine, $4 \mathrm{KCl}, 4 \mathrm{MgATP}$, and $0.3 \mathrm{Na}_{3} \mathrm{GTP}$. Osmolarity was adjusted to $280-310 \mathrm{mOsm}$. Briefly, animals were preimplanted with a 10-pins connector, a metal post, and a recording chamber under ketamine/xylazine anesthesia, and a craniotomy was performed at the coordinates for targeting the dorsal hippocampus $(1.6 \mathrm{~mm}$ posterior and $2.3 \mathrm{~mm}$ lateral from bregma). Before juxtacellular recordings, mapping experiments with low-resistance electrodes (0.5-1 $\mathrm{M} \Omega$ ) were performed to precisely estimate the location of the dorsal CA2 and CA3 region. Juxtacellular recordings in freely-moving mice were obtained by means of a miniaturized micromanipulator (secured onto a custommade base) and an ELC miniature headstage (connected to the preimplanted pin-connector), as previously described (Diamantaki et al., 2018). Recordings were performed while animals collected food pellets in an O-shaped, linear maze $(70 \times 50 \mathrm{~cm}$, 9-cm-wide path, $16-\mathrm{cm}$-high walls). Juxtacellular labeling was performed according to standard procedures (Pinault, 1994, 1996) with 200-ms-long squared current pulses. The juxtacellular voltage signal was acquired via an ELC miniature headstage (NPI Electronic), and an ELC-03XS amplifier (NPI Electronic), sampled at $20 \mathrm{kHz}$ by a POWER1401-3 analog-to-digital interface under the control of Spike2 Software (CED). The location of the animal was tracked using two LEDs (red and blue) mounted on the mouse's head. The LED position was acquired via a video $(25 \mathrm{~Hz}$ frame rate) with the IC Capture Software (The Imaging Source).

Dataset and cell identification. Recordings were performed at the coordinates for targeting the dorsal CA2/CA3 (see Juxtacellular recordings). The Pyr cell layer could be reliably identified by characteristic features of the local field potential (LFP) activity as well as multiunit activity, which was prominent within the layer when the animals were either anesthetized or awake resting. Entry into the stratum radiatum (SR) and stratum lacunosum moleculare (SLM) was usually associated with a drop in the electrode resistance and a progressive increase in the amplitude of LFP theta waves (Buzsáki, 2002). Thus, electrode resistance, extracellular multiunit activity, LFP theta, and juxtacellular hit rates served as reliable correlates of the electrode location within the CA2/CA3 Pyr layers. Indeed, histologic analysis confirmed the expected electrode location since, in the large majority of the cases (50 of 53) where the electrode was expected to be in the CA2/CA3 Pyr layers, neurons (or recording sites) within the CA2 or CA3 Pyr layer were recovered. Only in 3 cases, a CA1 neuron was recovered (not included in further analysis). The exact recording location was confirmed by post hoc histologic analysis and immunohistochemistry for the CA2-specific marker PCP4 (Kohara et al., 2014). This staining (along with others, Lein et al., 2005) clearly outlines the CA2 region as a cytochemically distinct region, which partially overlaps with anatomic boundaries. The soma of all identified Pyr neurons assigned to CA2 was located within the PCP4-positive area (see Fig. 2). In our dataset, two neurons were positive for PCP4 but were located within the CA3a (see Fig. 5). For consistency, these neurons were classified as CA3a neurons according to their anatomic locations, although their morphologic and electrophysiological features (see Fig. $4 N$ ) tended to be more similar to the CA2 population.

The dataset of recordings in freely-moving animals includes 174 recordings from active neurons, which were assigned to the CA2/CA3 region (a subset of recordings were reported previously in Diamantaki et al., 2018). Consistent with previous work, a considerable fraction of recorded neurons were silent during exploration of the environment (not shown), and these silent recordings were not included in the present analysis. Recordings were classified as Pyr or fast-spiking (FS) neurons based on firing rate and spike-width criteria, as previously described (Preston-Ferrer et al., 2016) (see Fig. 1A). FS classification criteria were confirmed by cell identification. In all cases, where a neuron with a narrow spike waveform $(<0.4 \mathrm{~ms}$ peak to trough) was labeled, a neuron displaying interneuronal morphologic features was recovered $(n=3$ FS neurons in freely-moving animals, see Fig. $1 A ; n=2$ FS neurons in 
A

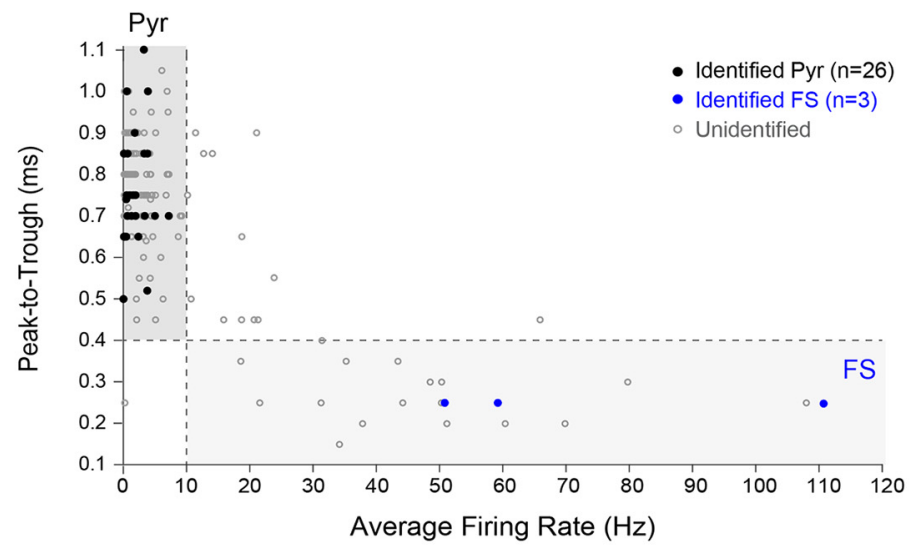

B
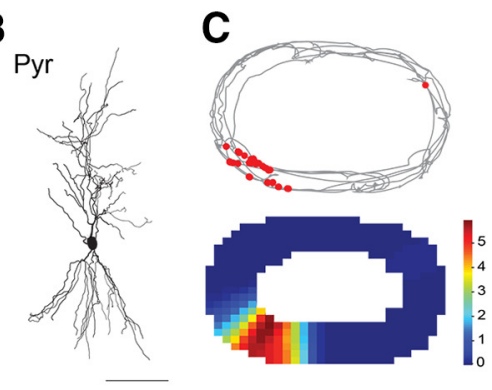

D


$\mathbf{F}$

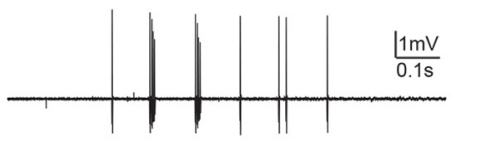

G

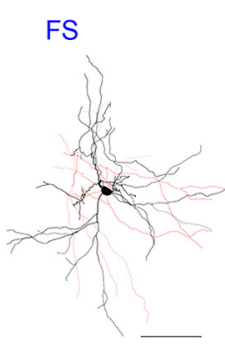

H

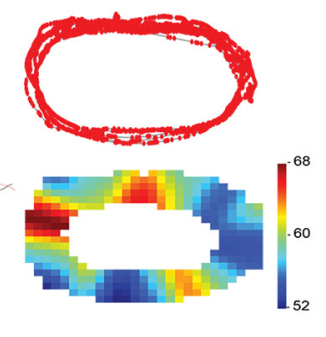

I


$\mathbf{L}$

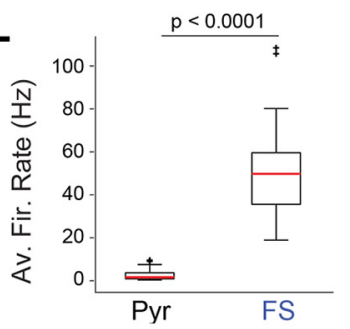

M

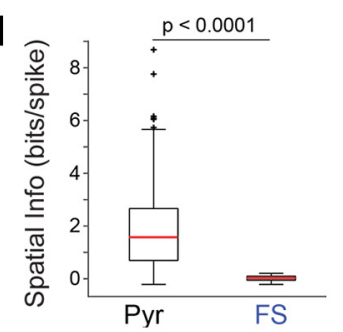

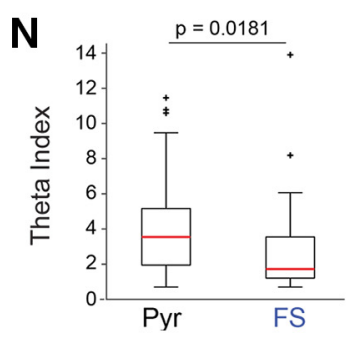

Figure 1. Juxtacellular recordings of $C A 2$ and $C A 3$ neurons in freely-moving mice. $A$, Scatterplot showing the distribution of spike-widths (assessed by peak-to-trough times) as a function of average firing rates for all active neurons $(n=174)$. Black dots represent morphologically identified Pyr cells (Pyr, $n=26)$. Blue dots represent identified FS interneurons $(n=3)$. Gray circles represent nonidentified recordings $(n=145)$. Dotted lines indicate the thresholds used for classification of Pyr $(n=140)$ and FS $(n=19)$, as in Preston-Ferrer et al. (2016). B, Reconstruction of the dendritic morphology of a representative CA2 Pyr neuron, recorded in a freely-moving mouse (recording shown in C. Scale bar, $100 \mu \mathrm{m}$. C, Spike-trajectory plot (top) and color-coded rate map (bottom) for the neuron shown in $\boldsymbol{B}$. Red dots represent action potentials. The color bar indicates firing rate $(\mathrm{Hz}) . \boldsymbol{D}$, Average spike waveform for the neuron shown in $\boldsymbol{B}$. $\boldsymbol{E}$, Spike-time autocorrelogram for the neuron shown in $\boldsymbol{B}$. The theta index value is indicated. $\boldsymbol{F}$, Representative high-pass filtered juxtacellular spike-trace for the neuron shown in $\boldsymbol{B}$. $\boldsymbol{G}$, Reconstruction of the dendritic (black) and local axonal (red; partial reconstruction) morphology of an identified FS interneuron, whose soma was located within the CA3a Pyr layer. Scale bar, $100 \mu \mathrm{m}$. $\boldsymbol{H}-\boldsymbol{K}$, Same as in $\mathbf{C}-\boldsymbol{F}$, except for the neuron shown in $\boldsymbol{G}$. Note the narrower spike waveform, lower spatial selectivity, and higher firing rate of the identified interneuron, compared with the Pyr cell. L-N, Boxplots showing average firing rates $(\boldsymbol{L})$, spatial information per spike $(\boldsymbol{M})$, and theta index $(\boldsymbol{M})$ for Pyr and FS recordings $(\boldsymbol{L}, \boldsymbol{M}$ : Pyr, $n=140 ; F S, n=19 ; \mathbf{N}$ : Pyr, $n=111 ; F S, n=19)$. Whiskers indicate 1.5 interquartile ranges. Outliers are shown as crosses. $p$ values are indicated (Wilcoxon rank-sum test).

anesthetized animals, not shown), consistent with previous observations (Fox and Ranck, 1981; Buetfering et al., 2014; Preston-Ferrer et al., 2016; Ognjanovski et al., 2017). In total, 26 Pyr cells and 3 FS interneurons were labeled and recovered in the CA2/ CA3. Principal cells were morphologically classified as Pyr if a Pyr-shaped soma and at least a prominent apical dendrite could be identified. The apical dendritic morphology of 21 of 26 Pyr neurons was reconstructed; these were selected for morphologic analysis due to their high-quality filling (of these, 17 neurons met the criteria for burstiness and were included in the analysis; see Fig. $4 N$ ). In additional 24 putative Pyr recordings, the recording site could be assigned based on post hoc histologic analysis (e.g., the recovery of electrode tracks and/or remains of cell debris). Together, including the identified recordings, the anatomic location of $50 \mathrm{Pyr}$ recordings could be assigned along the proximodistal CA2/CA3 axis (see Fig. 3). CA3a and $\mathrm{CA} 3 \mathrm{~b}$ were defined as equally wide subregions from proximal CA2 until distal CA3c (Oliva et al., 2016), with CA3c being the portion between the dentate gyrus blades (see also Scharfman, 1993; Hunsaker et al., 2008; Scharfman and Myers, 2012). The relative location of the recorded neurons along the transverse CA2/CA3 axis was determined, with 0 assigned to the CA2/CA1 border (defined either by the PCP4 immunohistochemistry or relative thickening of Pyr layer) and 1 to $\mathrm{CA} 3 \mathrm{~b} / \mathrm{CA} 3 \mathrm{c}$ border. We note that the conclusions of the present study do not critically depend on the definition of the $\mathrm{CA} 3 \mathrm{a} / \mathrm{b}$ boundary, since the analysis was based on normalized somatic locations along the proximodistal axis (see, e.g., Figs. 3, 4). Moreover, removing the few neurons $(n=2$; see Fig. $4 N$ ), which were located around the $\mathrm{CA3}$ a/b boundary did not affect the conclusions $\left(R^{2}=0.53 ; p=0.001\right)$.

Immunohistochemistry and neuronal reconstruction. For histologic processing, animals were killed with an overdose of pentobarbital and perfused transcardially with $0.1 \mathrm{M}$ PBS followed by a 4\% PFA solution. Brains were sliced on vibratome (VT1200S; Leica Microsystems) to obtain $70-\mu$ m-thick coronal sections. To reveal the morphology of juxtacellularly labeled cells (i.e., filled with neurobiotin), brain slices were processed with streptavidin-546 (Invitrogen) as described previously (Diamantaki et al., 2018). Immunohistochemical stainings for PCP4 were performed with the rabbit anti-PCP4 (catalog \#HPA005792, Sigma Millipore), as in previous work on hippocampal CA2 (e.g., Botcher et al., 2014; Hitti and Siegelbaum, 2014; Kohara et al., 2014; Meira et al., 2018). PCP4 expression within the hippocampus was consistent with previous work, with high immunoreactivity being observed in the CA2, granule cell layer, and fasciola cinerea (e.g., Kohara et al., 2014; Meira et al., 2018; Alexander et al., 2018; Swanson and Hahn, 2020) as well as scattered expression within the proximal CA1 and 
CA3a (e.g., San Antonio et al., 2014; Fernandez-Lamo et al., 2019; Swanson and Hahn, 2020). Immunostainings were performed on free-floating sections as described previously (Ray et al., 2014). Fluorescent images were acquired by epifluorescence microscopy (Axio imager; Carl Zeiss). After fluorescence images were acquired, the neurobiotin staining was converted into a dark $\mathrm{DAB}$ reaction product followed by $\mathrm{Ni}^{2+}-\mathrm{DAB}$ enhancement protocol (Klausberger et al., 2003). Neuronal reconstructions and quantifications of dendritic lengths were performed manually on DAB-converted specimens with Neurolucida software (MBF Bioscience), and displayed as $2 \mathrm{D}$ projections. The dendritic ratio was defined as the total apical dendritic length within the SLM divided by the total apical dendritic length. Digital reconstructions were not corrected for tissue shrinkage. However, from several measurements, shrinkage was determined to be $\sim 40 \%-50 \%$ along the $z$ axis, and negligible along the $x$ and $y$ axes $(\sim 10 \%) . z$ axis shrinkage correction led to qualitatively similar results and did not alter the statistical significance of our findings.

Analysis of electrophysiology data. Spike signals from juxtacellular voltage traces were manually isolated with the help of principal component analysis via custom-made codes written in MATLAB, as described previously (Burgalossi et al., 2011). The burst index was used as a measure of bustiness, and defined (as in Neunuebel and Knierim, 2012; Hunt et al., 2018) as the sum of spikes with an ISI $<6 \mathrm{~ms}$, divided by the total number of spikes. The theta index was used as a measure of spiking rhythmicity in the theta frequency range, and it was computed as in Yartsev et al. (2011) and defined as the average power within $1 \mathrm{~Hz}$ of the maximum of the autocorrelation function in the theta band divided by the average power between 1 and $50 \mathrm{~Hz}$. Only spike trains with $\geq 40$ spikes included in the analysis of burstiness and theta rhythmicity. Recordings (or portions of recordings) in which cellular damage was observed (e.g., spike-shape broadening, increase in firing rate accompanied by negative DC-shifts of the juxtacellular voltage signal, as described in Pinault, 1996; Herfst et al., 2012) were excluded from the analysis. In the present study (in line with previous work; Epsztein et al., 2011; D. Lee et al., 2012; Diamantaki et al., 2016a,b, 2018), a linear circular maze was used for enabling the assessment of spatial modulation in CA2/CA3 Pry neurons within shorter recording durations compared with extracellular recordings.

Experimental design and statistical analysis. No statistical methods were used to predetermine sample sizes, but our sample size estimates were based on previous work addressing structure-function relationships of single neurons with similar techniques (e.g., Tang et al., 2014b, 2015; Diamantaki et al., 2016a; Preston-Ferrer et al., 2016). Our samples are similar to those reported in previous publications. Neuronal reconstructions and morphologic analysis were performed blind to the electrophysiological data. Statistical analysis was performed with MATLAB. For linear regressions, adjusted coefficients of determination $\left(R^{2}\right)$ are reported. Statistical significance was assessed by a two-sided Wilcoxon rank-sum test with 95\% confidence intervals (Holm-Bonferroni correction for multiple comparisons). Data are presented as mean \pm Standard Deviation (SD), unless indicated otherwise.

Analysis of spatial modulation. The position of the mouse was defined as the midpoint between two head-mounted LEDs. For computing color-coded firing rate maps, only spikes during movement $(>1 \mathrm{~cm} /$ s) were included. Space was discretized into pixels of $2.5 \times 2.5 \mathrm{~cm}$, for which the occupancy $(z)$ of a given pixel $x$ was calculated as follows:

$$
z(x)=\sum_{t} w\left(\left|x-x_{t}\right|\right) \Delta t
$$

where $x_{t}$ is the position of the mouse at time $t, \Delta t$ the interframe interval, and $w$ a Gaussian smoothing kernel with $\sigma=0.5 \mathrm{~cm}$. Then, the firing rate (r) was calculated as follows:

$$
r(x)=\frac{\sum_{i} w\left(\left|x-x_{i}\right|\right)}{z}
$$

where $x_{\mathrm{i}}$ is the position of the mouse when spike $i$ was fired. The firing rate of pixels, whose occupancy $(z)$ was $<20 \mathrm{~ms}$, was not shown.
The spatial information of a cell in bits per spike (Markus et al., 1994) is calculated as follows:

$$
I_{\text {spike }}=\sum_{n}\left(p_{n} *\left(\frac{\lambda_{n}}{\lambda}\right) * \log _{2}\left(\frac{\lambda_{n}}{\lambda}\right)\right)
$$

where $p_{n}$ is the probability of the animal being in $\mathrm{n}$-th pixel bin, $\lambda_{n}$ is the mean firing rate in the $\mathrm{n}$-th pixel bin, and $\lambda$ is the overall mean fire rate of the cell.

To assess the statistical significance of spatial modulation, a standard shuffling procedure was used. Specifically, for each trail of the shuffling procedure, spike times were randomly time-shifted within $\pm 10 \mathrm{~s}$ window, with shifted spike times exceeding the total duration of a recording being wrapped around to the beginning of the recording. For each permutation, the spatial information was calculated, and the procedure reiterated 1000 times to generate a null distribution for each cell. A cell was defined as place cell when (1) its spatial information exceeded the 95th percentile of its null distribution (i.e., significantly spatially modulated), and (2) at least one place field $<300$ pixels was detected. In our dataset, 21 of 50 Pyr recordings, where anatomic location could be assessed, were significantly spatially modulated $(p<0.05)$; the large majority of them were classified as place cell (19 of 21) and displayed a single place field (18 of 19). In the remaining two recordings, a place field could not be detected (total pixels $>300$ ). The infield firing rate was calculated as the average firing rate over all place field pixels. To calculate the size of the place fields, a firing field was considered as at least 40 contiguous pixels with average firing rate exceeding $20 \%$ of the peak firing rate (Leutgeb et al., 2007; Neunuebel and Knierim, 2012).

\section{Results \\ Juxtacellular recordings and classification of CA2 and CA3 neurons}

To explore the structural correlates of neuronal activity in the CA2/CA3 region of the dorsal hippocampus, we used recently optimized juxtacellular recording procedures (Diamantaki et al., 2018) for monitoring the activity of single neurons while mice explored a familiar circular arena. Together, we juxtacellularly recorded 174 hippocampal neurons from freely-moving mice. Neurons were classified as putative Pyr neurons (Pyr, $n=140$ ) or FS interneurons $(n=19)$ based on spike-width and firing rate criteria (Fig. 1A). These criteria were consistent with previous studies (e.g., Fox and Ranck, 1981; Sik et al., 1995; Preston-Ferrer et al., 2016) and were further confirmed by juxtacellular labeling procedures, in that all identified neurons, for which morphology could be assessed, were correctly classified as Pyr cells $(n=26)$ or FS interneurons $(n=3)$ (Fig. $1 A$; for details, see Materials and Methods).

A representative CA2 Pyr neuron, recorded in a freely-moving mouse, is shown in Figure $1 B-F$. This neuron displayed classical morphologic features of hippocampal Pyr cells (Fig. 1B) (e.g., an apical dendritic tree, which extends within the SR and SLM), while basal dendrites are largely restricted to the stratum oriens (SO). Consistent with the CA2 location, but unlike CA3 Pyr cells (Li et al., 1994; Ishizuka et al., 1995), this neuron did not display complex spines (thorny excrescences) on the dendrites (not shown). During spatial exploration, this neuron displayed spatially localized spiking (Fig. 1C), a defining signature of place cell activity. Consistent with our Pyr cell classification criteria, this neuron fired at a low rate (average firing rate: $0.65 \mathrm{~Hz}$ ) and displayed broad spike waveform (Fig. $1 D$; peak-totrough time $=0.85 \mathrm{~ms}$ ). A large fraction of spikes occurred within bursts and was rhythmically entrained by LFP theta oscillations (4-12 Hz; Fig. 1E,F). 
Three identified neurons displayed the classical morphologic features of interneurons. A representative example of an FS interneuron, recorded in a freely-moving mouse, is shown in Figure $1 G-K$. The soma of this neuron was located within the CA3 Pyr layer. A dense axonal plexus was recovered (and only partially reconstructed in Fig. 1G), which extended primarily within the Pyr layer, but also within the neighboring SR and SO. Consistent with our FS cell classification criteria, this neuron fired at a high rate (average firing rate: $59.2 \mathrm{~Hz}$; Fig. $1 \mathrm{H}$ ) and displayed narrow spike waveform (Fig. 1I; peak-to-trough time $=0.25 \mathrm{~ms}$ ). During spatial exploration, spiking activity was not spatially selective (Fig. $1 H$ ), and it was entrained by the LFP theta oscillations (Fig. 1J,K).

Together, in our dataset, 140 neurons were classified as Pyr and 19 as FS interneurons. As expected, Pyr neurons fired at much lower rates (Fig. $1 L$; average firing rates: Pyr, $2.16 \pm 2.12 \mathrm{~Hz}$; FS, $52.97 \pm 25.02 \mathrm{~Hz} ; p=1.11 \mathrm{e}-24)$ and carried significantly more spatial information compared with FS neurons (Fig. $1 M$; spatial information per spike: Pyr, $1.94 \pm 1.63$ bits; FS, $0.01 \pm 0.04$ bits; $p=3.27 \mathrm{e}-17)$. Notably, the entrainment of spiking activity by theta LFP oscillations, as assessed by the standard theta index (see Materials and Methods) was significantly lower in putative FS compared with Pyr neurons (Fig. $1 N$; theta index; Pyr, $3.90 \pm 2.49$; FS, $2.97 \pm 3.34 ; p=0.018)$. This is in remarkable contrast to other regions of the hippocampal formation (e.g., the CA1 region) where strong theta entrainment of spiking activity is a classical defining feature of putative FS interneurons (classically referred to as theta cells) (Ranck, 1973).

\section{Spatial and temporal activity patterns of CA2 and CA3 neurons}

Next, we compared the spatial and temporal spiking properties of CA2/CA3 Pyr neurons. For simplicity, recordings were assigned to CA2, CA3a, or CA3b, based on cell identification or unequivocal assignment of the recording locations from post hoc histology and PCP4 immunohistochemistry (details in Materials and Methods; see also Fig. 2). Together, 15 recordings could be assigned to the CA2, 21 to the CA3a, and 14 to the CA3b region. In line with previous extracellular studies (H. Lee et al., 2015; Lu et al., 2015; Oliva et al., 2016), a considerable fraction of active Pyr neurons along the proximodistal CA2/CA3 axis displayed spatially localized activity ( $\sim 38 \% ; 19$ of 50 active neurons classified as place cells; for details, see Materials and Methods). Representative recordings from identified place cells in the CA2, $\mathrm{CA} 3 \mathrm{a}$, and CA3b regions are shown in Figure $3 A$. The distribution of place cells tended to be lower in the CA2 (4 of 15) compared with the neighboring CA3 region (15 of 35), although this trend did not reach statistical significance. While average firing rates were not significantly different between CA2 and CA3 neurons (average firing rates: CA2, $1.97 \pm 2.38 \mathrm{~Hz} ; \mathrm{CA} 3,1.74 \pm 1.45 \mathrm{~Hz}$; $p=0.73$ ), we observed a trend for higher average in-field firing rates for CA2 place cells (Fig. 3B,C).

Next, we analyzed the burst propensity of CA2 and CA3 Pyr neurons. To this end, we computed the burst index (defined as the fraction of spikes with ISI $\leq 6 \mathrm{~ms}$ ) (Neunuebel and Knierim, 2012; Hunt et al., 2018) and calculated the fraction of spikes fired within bursts. We found that, in line with previous work (Oliva et al., 2016), burst propensity and topographical location along the proximodistal axis were significantly correlated (Fig. 3D,E; $R^{2}=0.30, p=0.00013$ ), with CA2 cells displaying the highest burst propensity, followed by CA3a and CA3b neurons (Fig. $3 D$ $F)$. A similar trend along the proximodistal axis was also observed when burst indices were computed for place cells alone
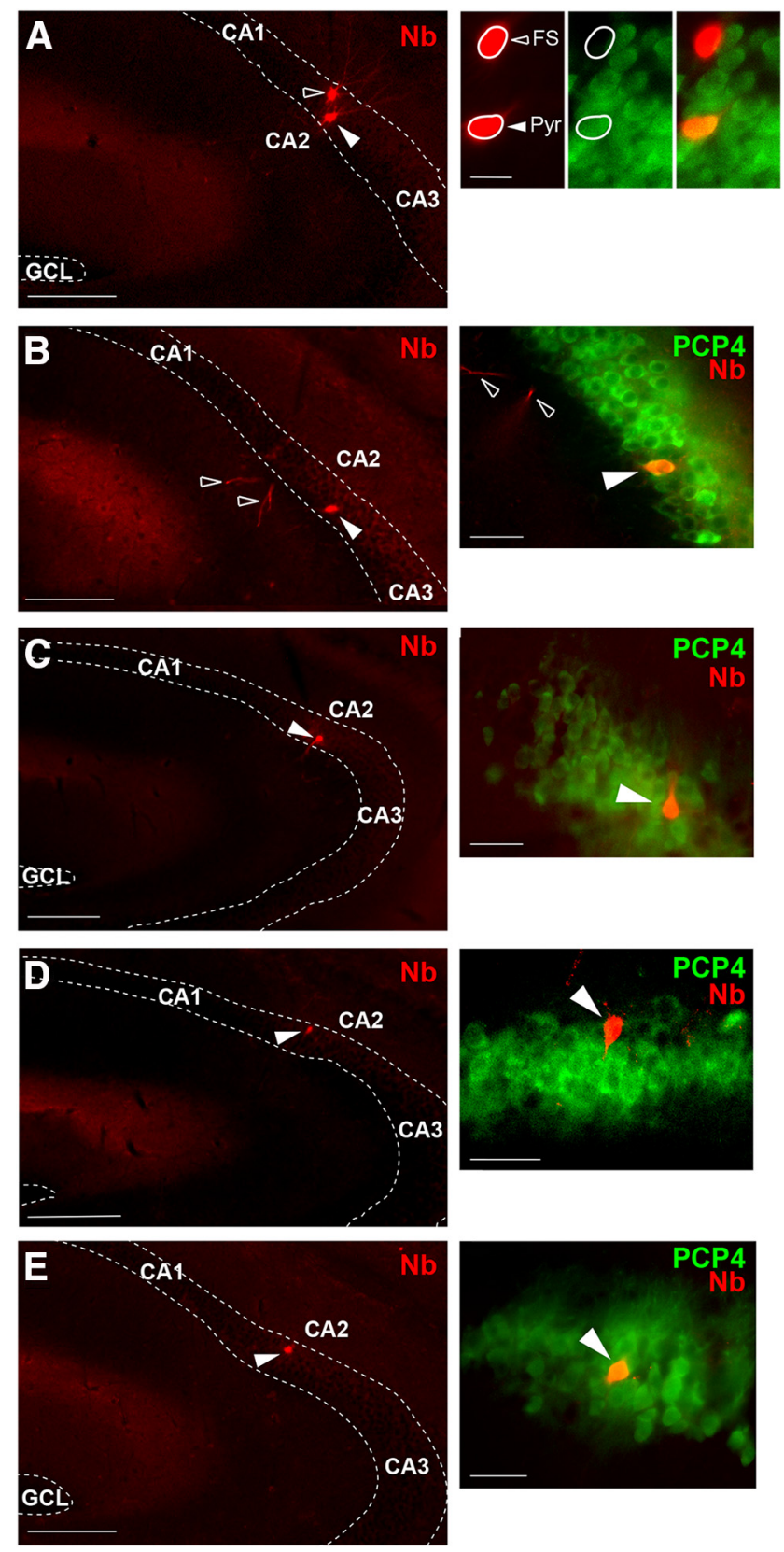

Figure 2. Identified CA2 Pyr neurons. $\boldsymbol{A}-\boldsymbol{E}$, Epifluorescence pictures showing PCP4 staining (green) and juxtacellularly labeled CA2 Pyr neurons (red), recorded in freely-moving mice (dataset related to Fig. 4M,N). Left panels, Low-magnification pictures (Pyr layer outlined as dotted lines). Right panels, High-magnification pictures, showing the location of the Pyr cell somata within CA2. A, Two neurons were sequentially labeled on the same electrode penetration: one FS cell (empty arrowhead) and one Pyr neuron (full arrowhead). The FS interneuron was negative for PCP4 expression, in line with previous observations (Kohara et al., 2014). B, Two CA2 Pyr neurons were labeled: one cell on a medial electrode penetration (dendrites indicated by the empty arrowhead), and another one on a more lateral penetration (full arrowhead). GCL, Granule cell layer; Nb, neurobiotin. Scale bars: $\boldsymbol{A}, 200 \mu \mathrm{m}$, Inset, $25 \mu \mathrm{m} ; \boldsymbol{B}-\boldsymbol{E}, 200 \mu \mathrm{m}$, Insets, $50 \mu \mathrm{m}$.

(not shown). CA2 neurons also fired significantly more spikes per bursts compared with neighboring CA3a and CA3b neurons (Fig. $3 G, H ; R^{2}=0.28, p=0.00048$ ).

In line with previous observations, this analysis indicates that spatial and temporal spiking properties of CA3 Pyr neurons are organized along a proximodistal gradient, which extends to the CA2 region. Notably, while being less spatially modulated (see also Cirulli et al., 2015; H. Lee et al., 2015; Oliva et al., 2016), 
CA2 Pyr neurons are more excitable than neighboring CA3 Pyr cells, as indicated by their higher spiking rates and burst propensity (Fig. 3C,F).

\section{Structure-function relationships of $\mathrm{CA} 2$ and $\mathrm{CA} 3$ neurons}

Several structural and electrophysiological features of CA2 and CA3 Pyr neurons change according to their topographical location; however, even at the same proximodistal level, morphologically and electrophysiologically distinct cell types are intermingled (Sun et al., 2017; Raus Balind et al., 2019), thus raising the question of whether and how Pyr cell diversity relates to in vivo spiking patterns during behavior. Given the strong contribution of perforant path inputs to the generation of spikebursts in CA2 and CA3 Pyr neurons (Sun et al., 2014, 2017; Helton et al., 2019), we hypothesized that the proportion of dendritic length within the SLM could correlate with burst propensity. To address this question, we reconstructed the dendritic morphologies of 17 Pyr neurons, which were selected for the morphologic analysis due to their high-quality filling (see Materials and Methods). We focused our analysis on the apical dendritic morphology, and quantified the dendritic lengths in the input layers (SLM and SR). Figure 4A$L$ shows three representative recordings from identified CA2 and CA3 neurons. The CA2 representative Pyr neuron displayed a large proportion of apical dendritic length within the SLM, as quantified by the dendritic ratio (dendritic length within SLM/total dendritic length $=0.49$; see Fig. $4 A$; Materials and Methods). During spatial exploration, this neuron displayed place-cell activity (Fig. 4B) and a large proportion of spikes was fired at short ISIs (Fig. $4 C, D$; burst index $=0.55$ ). Similar to the CA2 neuron, spiking activity of the representative CA3a and CA3b Pyr cells was also spatially modulated (Fig. $4 E, F$ ); however, the proportion of dendritic length within the SLM displayed a decreasing trend toward CA3b (Fig. 4A,E,I) along with a reduced tendency to fire spikes at short ISIs (Fig. $4 G, H$ and Fig. $4 K, L$ ). At the population level, we indeed found a significant correlation between burst index and dendritic ratios (Fig. $4 M, N ; R^{2}=0.44, p=0.0021$ ), indicating that during unrestrained behavior, neurons with a higher proportion of dendritic length in the SLM display a higher burst propensity.

Since a recent study proposed that bursting CA3 Pyr neurons comprise a novel Pyr cell class that lacks thorny excrescences (Hunt et al., 2018), we examined the morphologic features of the proximal dendrites of our identified neurons. We confirmed that, in line with previous work (Li et al., 1994; Ishizuka et al., $1995)$, all neurons that were classified as CA2 Pyr cells $(n=5)$ lacked thorny excrescences, while 10 of 12 neurons located within the CA3 region displayed (often multiple) thorny excrescences on their proximal dendrites. In the two remaining neurons, which were located in the CA3a region, we did not observe
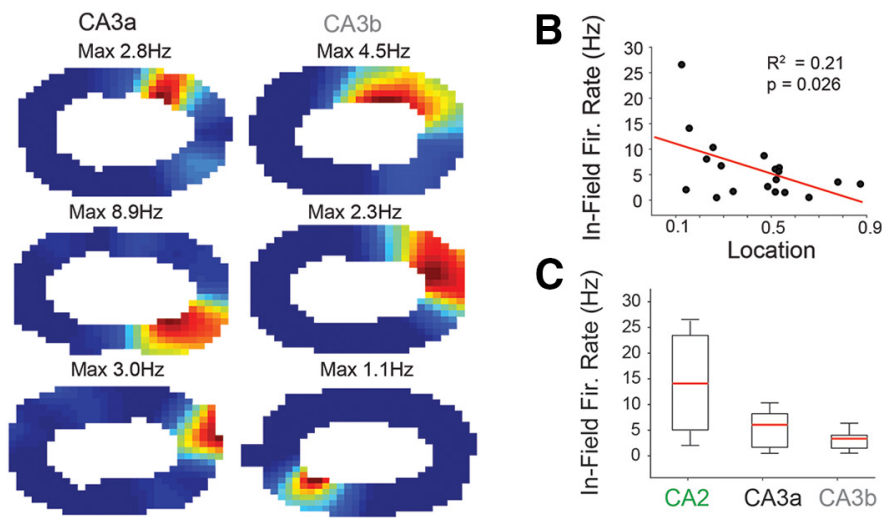

G

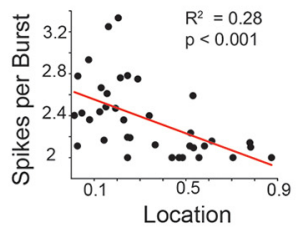

$\mathbf{F}$
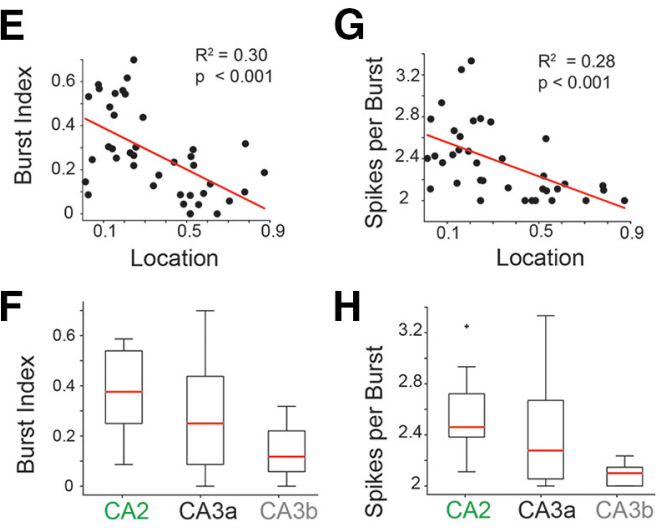

Figure 3. Spatiotemporal firing properties of CA2 and CA3 neurons. $A$, Representative rate maps of place cells in CA2 (left column), CA3a (middle column), and CA3b (right column). Maximal firing rates are indicated. $\boldsymbol{B}$, Scatter plot showing the distri作 recordings included in the analysis; see Materials and Methods). $\boldsymbol{G}, \boldsymbol{H}$, Same as in $\boldsymbol{E}, \boldsymbol{F}$, but for the average number of spikes per burst. Outliers in $\boldsymbol{H}$ are indicated as crosses.

thorny excrescences; these two neurons were however positive for the CA2-specific marker PCP4, indicating that they might represent displaced CA2 cells (Fig. 5).

Together, these results indicate that along the CA2/CA3 proximodistal axis, the burst propensity of individual Pyr neurons correlates with the relative amount of dendritic length sampling entorhinal inputs in the SLM. We propose that in vivo, during spatial exploration, the relative weights of entorhinal versus associational inputs determines the bursting behavior of individual $\mathrm{CA} 2$ and CA3 neurons.

\section{Discussion}

Resolving structure-function relationships within neural circuits is an essential step toward a mechanistic understanding of brain function. Structural variations in dendritic architecture, a key feature which determines the input field, as well as the integrative and computational properties of the neurons (Vetter et al., 2001; Schaefer et al., 2003; London and Häusser, 2005; Runyan and Sur, 2013; Stuart and Spruston, 2015), are prominent even within the same cell class. In vitro and modeling work has indeed demonstrated that variations in dendritic morphology alone can drastically impact neuronal function (Jaffe and Carnevale, 1999; Vetter et al., 2001; Krichmar et al., 2002; Schaefer et al., 2003; 

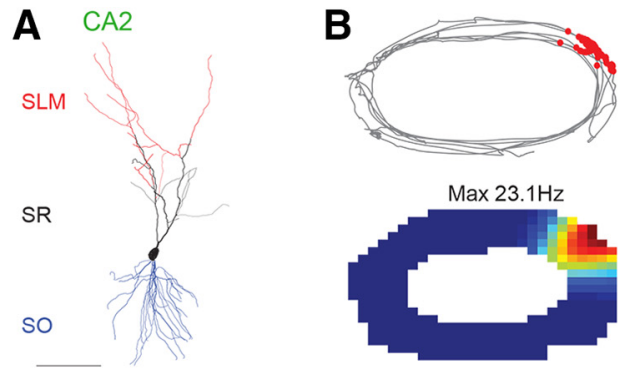

Dendr. Ratio $=0.49$

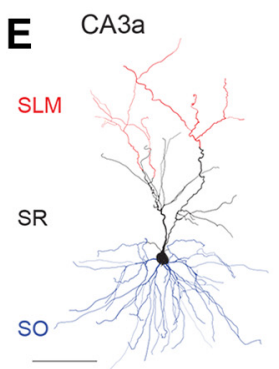

Dendr. Ratio $=0.47$

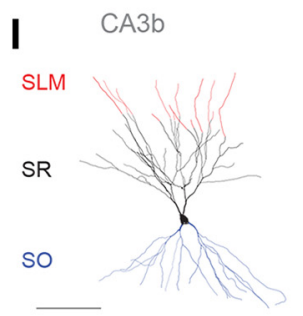

Dendr. Ratio $=0.21$

$\mathbf{F}$
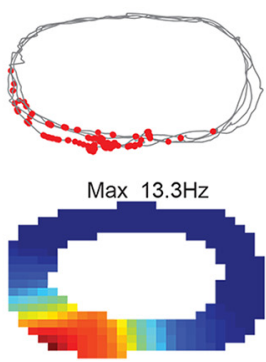

$\mathbf{J}$

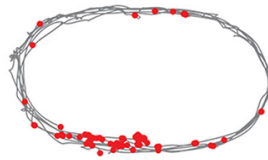

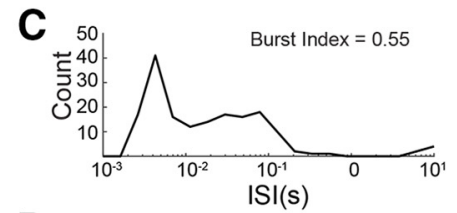
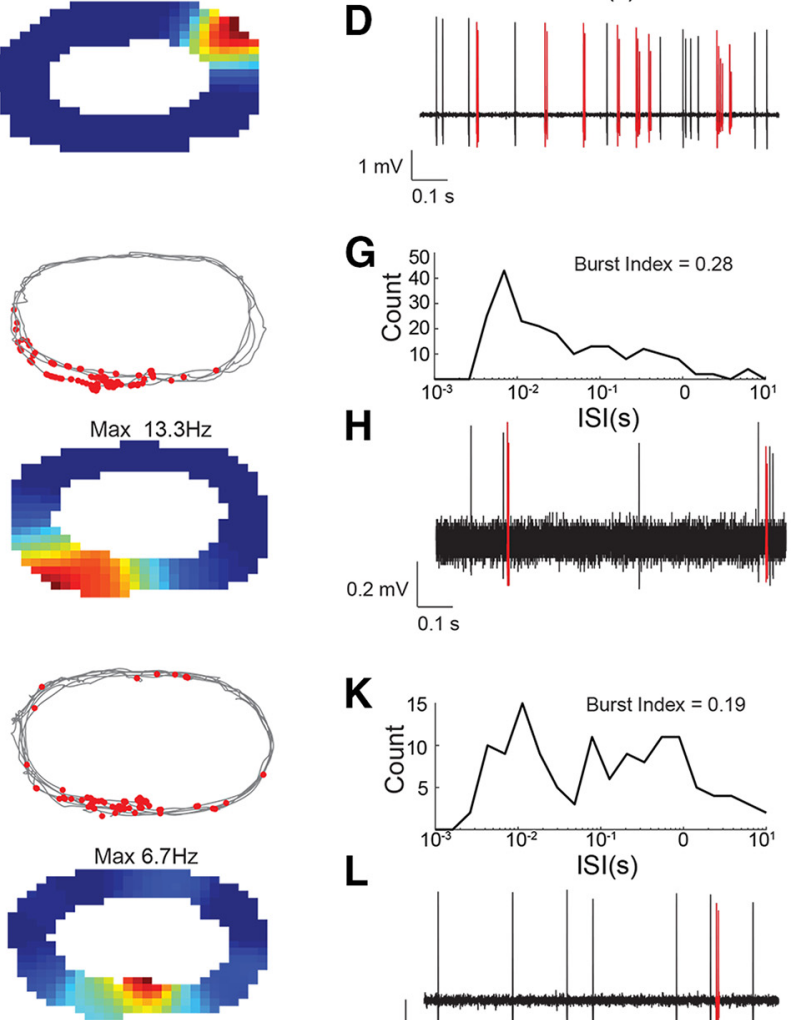
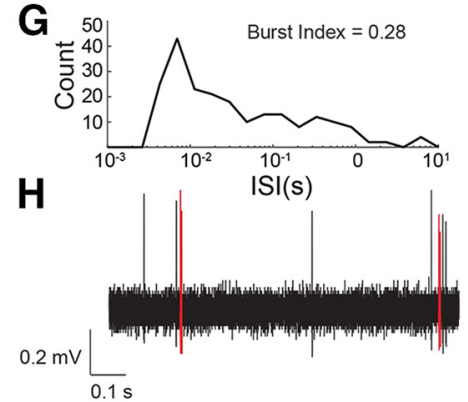

K

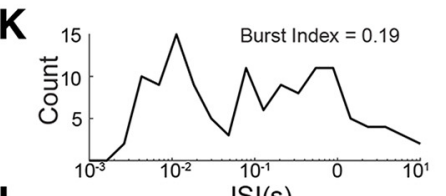

$\mathbf{L}$

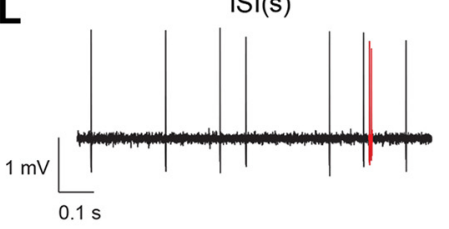

N



Figure 4. Morphologic correlates of spike-burst activity in CA2 and CA3 neurons. $A$, Reconstruction of the dendritic morphology of a representative CA2 Pyr neuron, recorded in a freely-moving mouse (recording shown in $\boldsymbol{B}$ ). The proportion of dendrites located within the SLM (red) and SR (black), and the corresponding dendritic ratio are indicated. Blue represents basal dendrites. Scale bar, $100 \mu \mathrm{m}$. $\boldsymbol{B}$, Spike-trajectory plot (top) and color-coded rate map (bottom) for the neuron shown in $\boldsymbol{A}$. Red dots represent action potentials. Maximal firing rate is indicated. $\boldsymbol{C}$, Distribution of ISIs for the neuron shown in $\boldsymbol{A}$. The burst index is indicated. $\boldsymbol{D}$, Representative high-pass filtered juxtacellular spike trace for the neuron shown in $\boldsymbol{A}$. Red represents bursty spikes (ISI $\leq 6 \mathrm{~ms}$ ). $\boldsymbol{E}-\boldsymbol{H}$, Same as in $\boldsymbol{A}-\boldsymbol{D}$, but for a CA3a neuron. $\boldsymbol{I} \boldsymbol{- L}$, Same as in $\boldsymbol{A}-\boldsymbol{D}$, but for a CA3b neuron. $\boldsymbol{M}$, Schematic outline of the Pyr layer showing the somatic location of the reconstructed Pyr neurons included in the bustiness analysis $(\boldsymbol{N})$ : CA2 neurons (green dots, $n=5$; see also Fig. 2), CA3a neurons (black dots, $n=6$ ), CA3b neurons (gray dots, $n=6)$. The two numbers $(1,2)$ indicate the two CA3 neurons, which were positive for the CA2 marker PCP4 (Fig. 5). $\boldsymbol{N}$, Scatter plot showing the burst index as a function of dendritic ratio $(n=17$, shown in $\boldsymbol{M})$. Same conventions as in $\boldsymbol{M}$. Red represents linear regression line. $R^{2}$ and $p$ values are indicated.

Weaver and Wearne, 2008) and have thus led support to the idea that neuronal function might follow structure (Connors and Regehr, 1996). It is however currently unknown whether and how the variability in dendritic architecture is related to neuronal activity in the intact system (i.e., in vivo during behavior).

In this study, we explored this issue in the CA2 and CA3 region of the rodent hippocampus. By recording and labeling single neurons in freely-moving mice, we found that, in line with previous studies, the topographical location of Pyr neurons is a strong correlate of in vivo activity patterns. Moreover, we showed that burst propensity of single Pyr neurons correlates with dendritic architecture: Pyr neurons with a higher proportion of dendritic length within the SLM (i.e., higher dendritic ratio; see Fig. $4 N$ ) displayed a higher tendency to fire spikebursts. In the present study, we primarily focused on neuronal dendritic architecture, since it determines the input field of a neuron, and hence sets the amount and origin of excitatory inputs. Our results thus indicate that inputs from the entorhinal cortex are likely to play a crucial role for determining the in vivo temporal spiking properties of CA2/CA3 Pyr neurons during natural behavior. Indeed, entorhinal input strength is strongest within the CA2 and decreases toward the proximal CA3 (Sun et al., 2014, 2017; Helton et al., 2019), paralleled by graded changes in the dendritic morphology of Pyr neurons along this axis (Ishizuka et al., 1995; Sun et al., 2017). Future work will be required to extend the observations of the present study, and to resolve whether and how other cellular features (e.g., axonal morphology, intrinsic properties, and/or network mechanisms) contribute to in vivo Pyr cell excitability (Kole, 2011; Thome et al., 2014; Rama et al., 2017).

A recent study also proposed that spike-bursts might be preferentially contributed by a specific subclass of Pyr neurons, which lack thorny excrescences on their proximal dendrites (Hunt et al., 2018). In our study, all identified CA3 neurons displayed thorny excrescences (as in Raus Balind et al., 2019). The only two neurons lacking thorny excrescences were positive for the CA2-specific marker PCP4 (see Materials and Methods). Given that PCP4 labels scattered cells within the CA3a as well (Lein et al., 2005; Sun et al., 2017; Hunt et al., 2018; Fernandez-Lamo et al., 2019), we speculate that athorny Pyr neurons within CA3 might be preferentially contributed by displaced CA2 neurons. However, given the limited number of observations, we cannot exclude that athorny (PCP4 negative) CA3 Pyr neurons went undetected in the present study.

Our results align with previous work, which demonstrated that structural and functional properties of CA2/CA3 neurons are organized topographically (H. Lee et al., 2015; Lu et al., 2015; Oliva et al., 2016). Specifically, place cell properties were shown to change gradually along the proximodistal axis. On average, CA2 units tended to be less spatially modulated and to display 
A

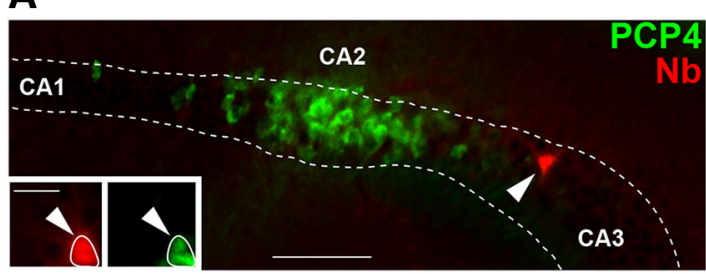

D

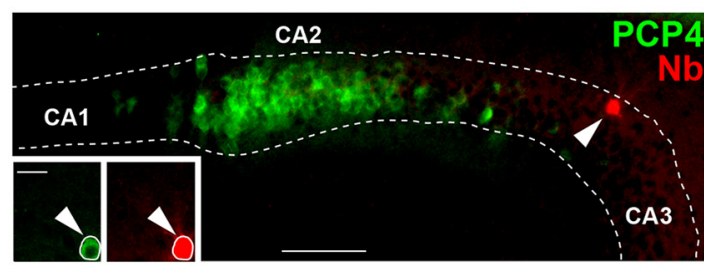

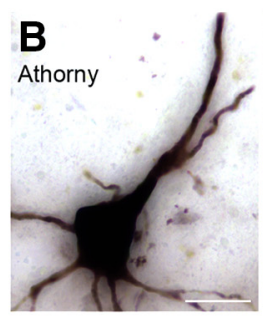

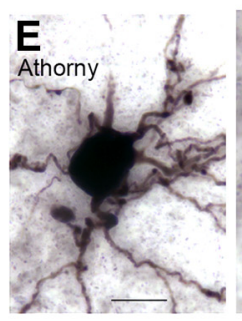

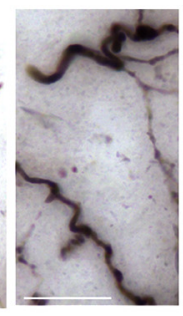

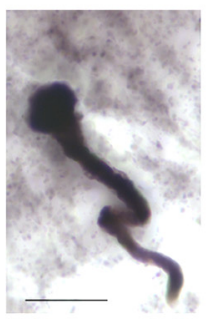

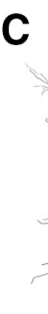

C

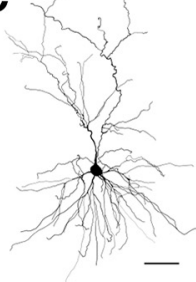

$\mathbf{F}$

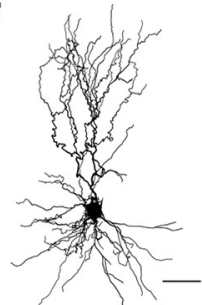

G
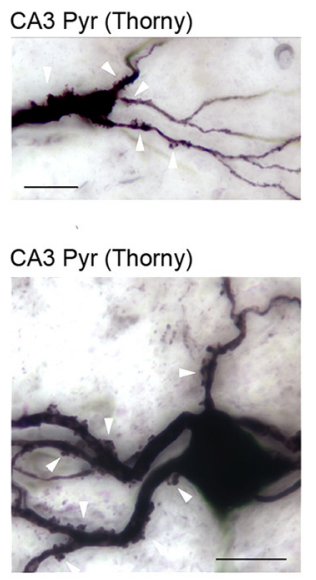

Figure 5. Identified PCP4-positive CA3a neurons. A, Epifluorescence pictures showing PCP4 staining (green) and a PCP4-positive CA3a Pyr neuron (Nb, neurobiotin, in red; see arrowhead), recorded in freely-moving mice (indicated by 1 in Fig. 4M,N). Bottom left, High-magnification view of the Pyr cell soma. Scale bars: $100 \mu \mathrm{m}$; Inset, $20 \mu \mathrm{m}$. B, Maximum intensity z-stack projections of the neuron in A after DAB conversion (see Materials and Methods), showing the soma (left) and proximal apical dendritic segments (right). Note the absence of thorny excrescences. Scale bars, $15 \mu \mathrm{m}$. $\boldsymbol{C}$, Reconstruction of the dendritic morphology of the neuron shown in $\boldsymbol{A}, \boldsymbol{B}$. Scale bar, $50 \mu \mathrm{m}$. $\boldsymbol{D}-\boldsymbol{F}$, Same as in $\boldsymbol{A}-\boldsymbol{C}$, but for another PCP4-positive Pyr located in CA3a (indicated by 2 in Fig. $4 M, M)$. Scale bars, same as in $\boldsymbol{A}-\boldsymbol{C}$. $\boldsymbol{G}$, Maximum intensity $z$-stack projections of two representative CA3 cells, showing the presence of thorny excrescences on proximal dendritic segments (some are indicated by white arrowheads). Scale bars, $15 \mu \mathrm{m}$.

multiple place fields compared with the proximal and distal CA3 (H. Lee et al., 2015; Lu et al., 2015; Oliva et al., 2016). In our dataset, possibly due to the relatively small environment and shorter recording durations compared with previous extracellular studies, the large majority of spatially modulated neurons displayed a single place field (see Materials and Methods; Fig. 3). Notably, place cells with single fields tended to be sharper in CA2 compared with $\mathrm{CA} 3$, as indicated by the tendency toward higher infield firing rates (Fig. $3 B, C$ ) and smaller place field sizes in CA2 (CA2, $53.3 \pm 6.8$ pixels; CA3, $95.3 \pm 48.8$ pixels; $p=0.033$ ). However, the lower proportion of place cells in CA2, along with the relative instability of their place fields (H. Lee et al., 2015; Mankin et al., 2015), indicates that this region might be preferentially involved in the processing of nonspatial information (Alexander et al., 2016; Dudek et al., 2016; Meira et al., 2018). Future work should resolve whether distinct neural coding properties (e.g., spatial vs nonspatial) relate to different morphologic cell types within the CA2 region (Bartesaghi and Ravasi, 1999; Helton et al., 2019).

Spike-bursts have been described in a variety of systems, from invertebrate sensory systems to mammalian end-brain structures, and their occurrence in vivo is thought to be of special importance for neural circuit function. They have been proposed to serve at least three main roles: to encode specific stimulus features, to allow reliable information transfer to downstream targets, and to induce synaptic plasticity (for review, see Lisman, 1997; Izhikevich et al., 2003; Krahe and Gabbiani, 2004). Classically, spike-bursts are thought of as associative plasticity signals. According to the canonical model (Larkum et al., 1999; Takahashi and Magee, 2009), the concomitant activation of proximal and distal inputs onto a single Pyr neuron is transformed into a specific spike-burst pattern, which can in turn induce long-lasting changes in synaptic efficacy (Rebola et al., 2017). Recent work in the CA3 region (Raus Balind et al., 2019) has revealed distinct rules for the induction of spike-bursts: while regular-spiking CA3 Pyr neurons could be induced to fire spikebursts by strong proximodistal input activation (in line with the canonical model), a population of CA3 neurons (referred to as intrinsically bursty cells) was able to generate bursts, even in response to strong activation of local synaptic inputs onto the same dendritic segment. The relative abundance of regular-spiking and intrinsically bursty cells was partially related to their topographical position; however, both cell types could be observed at any proximodistal level (Raus Balind et al., 2019). Thus, any CA3 neuron is capable of generating spike-bursts (Kowalski et al., 2016; Raus Balind et al., 2019), depending on the specific pattern of input activation, thus raising the possibility that different burst mechanisms might be engaged under different behavioral states and/or experimental conditions. In the present study, we showed that, during spatial exploration, burst propensity of individual CA2/CA3 Pyr neurons correlates with the relative amount of dendritic length within the SLM, indicating that the relative weight of entorhinal inputs might determine burst firing on the recipient Pyr neurons.

This structure-function scheme indicates that morphologically distinct Pyr cell types might differentially contribute to hippocampal memory functions. During memory formation, CA2 and CA3 activity patterns are thought to become rapidly associated with the entorhinal inputs (which carry the episodic information) and with themselves, through the strong recurrent collaterals. By means of these associations, partial memory retrieval cues (likely provided by the entorhinal inputs) are then able to retrieve the stored memory engram, a process known as pattern completion (Rolls and Treves, 1994; Knierim and Neunuebel, 2016; Rebola et al., 2017). Notably, burst activity has been postulated to be important for the initial establishment of a memory trace, as well for its recall during memory retrieval (Treves and Rolls, 1992; Kaifosh and Losonczy, 2016). We speculate that Pyr neurons with a high dendritic ratio might act as drivers in these memory processes. Their selective recruitment via entorhinal inputs might trigger burst firing, which could serve as the initial activity bias for pattern completion within the CA2/CA3 network. Indeed, spike-bursts within the CA3 network are exceptionally powerful, with even single spike-bursts being sufficient for initiating global network synchronization events (de la Prida et al., 2006; Wittner and Miles, 2007; Marissal et al., 
2012). We speculate that selective activity manipulations of these driver neurons during memory processing can be sufficient for biasing pattern completion dynamics within the CA2/CA3 network.

In conclusion, our study provides direct anatomic evidence that distinct spatiotemporal activity patterns of CA2/CA3 Pyr neurons, assessed in vivo during natural behavior, relate to their topographical positon and dendritic architecture. Future studies, possibly using genetic tagging approaches, will be required to resolve causal relationships between Pyr cell morphologies and hippocampal memory processing.

\section{References}

Alexander GM, Brown LY, Farris S, Lustberg D, Pantazis C, Gloss B, Plummer NW, Jensen P, Dudek SM (2018) CA2 neuronal activity controls hippocampal low gamma and ripple oscillations. Elife 7:e38052.

Alexander GM, Farris S, Pirone JR, Zheng C, Colgin LL, Dudek SM (2016) Social and novel contexts modify hippocampal CA2 representations of space. Nat Commun 7:10300.

Bartesaghi R, Ravasi L (1999) Pyramidal neuron types in field CA2 of the guinea pig. Brain Res Bull 50:263-273.

Bittner KC, Grienberger C, Vaidya SP, Milstein AD, Macklin JJ, Suh J, Tonegawa S, Magee JC (2015) Conjunctive input processing drives feature selectivity in hippocampal CA1 neurons. Nat Neurosci 18:11331142 .

Bittner KC, Milstein AD, Grienberger C, Romani S, Magee JC (2017) Behavioral time scale synaptic plasticity underlies CA1 place fields. Science 357:1033-1036.

Botcher NA, Falck JE, Thomson AM, Mercer A (2014) Distribution of interneurons in the CA2 region of the rat hippocampus. Front Neuroanat $8: 104$.

Buetfering C, Allen K, Monyer H (2014) Parvalbumin interneurons provide grid cell-driven recurrent inhibition in the medial entorhinal cortex. Nat Neurosci 17:710-718.

Burgalossi A, Herfst L, von Heimendahl M, Förste H, Haskic K, Schmidt M, Brecht M, von Heimendahl M, Förste H, Haskic K, Schmidt M, Brecht M, von Heimendahl M, Förste H, Haskic K, Schmidt M, Brecht M (2011) Microcircuits of functionally identified neurons in the rat medial entorhinal cortex. Neuron 70:773-786.

Buzsáki G (2002) Theta oscillations in the hippocampus. Neuron 33:325340.

Cirulli ET, Lasseigne BN, Petrovski S, Sapp PC, Dion PA, Leblond CS, Couthouis J, Lu YF, Wang Q, Krueger BJ, Ren Z, Keebler J, Han Y, Levy SE, Boone BE, Wimbish JR, Waite LL, Jones AL, Carulli JP, DayWilliams AG, et al. (2015) Exome sequencing in amyotrophic lateral sclerosis identifies risk genes and pathways. Science 347:1436-1441.

Connors BW, Regehr WG (1996) Neuronal firing: does function follow form? Curr Biol 6:1560-1562.

de la Prida LM, Huberfeld G, Cohen I, Miles R (2006) Threshold behavior in the initiation of hippocampal population bursts. Neuron 49:131-142.

Diamantaki M, Frey M, Berens P, Preston-Ferrer P, Burgalossi A (2016a) Sparse activity of identified dentate granule cells during spatial exploration. eLife 5:e20252.

Diamantaki M, Frey M, Preston-Ferrer P, Burgalossi A (2016b) Priming spatial activity by single-cell stimulation in the dentate gyrus of freely moving rats. Curr Biol 26:536-541.

Diamantaki M, Coletta S, Nasr K, Zeraati R, Laturnus S, Berens P, PrestonFerrer P, Burgalossi A (2018) Manipulating hippocampal place cell activity by single-cell stimulation in freely moving mice. Cell Rep 23:32-38.

Dudek SM, Alexander GM, Farris S (2016) Rediscovering area CA2: unique properties and functions. Nat Rev Neurosci 17:89-102.

Eichenbaum H (2017) On the integration of space, time, and memory. Neuron 95:1007-1018.

Epsztein J, Brecht M, Lee AK (2011) Intracellular determinants of hippocampal CA1 place and silent cell activity in a novel environment. Neuron 70:109-120.

Fernandez-Lamo I, Gomez-Dominguez D, Sanchez-Aguilera A, Oliva A, Morales AV, Valero M, Cid E, Berenyi A, Menendez de la Prida L (2019) Proximodistal organization of the CA2 hippocampal area. Cell Rep 26:1734-1746
Fox SE, Ranck JB (1981) Electrophysiological characteristics of hippocampal complex-spike cells and theta cells. Exp Brain Res 41:399-410.

Helton TD, Zhao M, Farris S, Dudek SM (2019) Diversity of dendritic morphology and entorhinal cortex synaptic effectiveness in mouse CA2 pyramidal neurons. Hippocampus 29:78-92.

Herfst L, Burgalossi A, Haskic K, Tukker JJ, Schmidt M, Brecht M (2012) Friction-based stabilization of juxtacellular recordings in freely moving rats. J Neurophysiol 108:697-707.

Hitti FL, Siegelbaum SA (2014) The hippocampal CA2 region is essential for social memory. Nature 508:88-92.

Hunsaker MR, Rosenberg JS, Kesner RP (2008) The role of the dentate gyrus, $\mathrm{CA} 3 \mathrm{a}, \mathrm{b}$, and $\mathrm{CA} 3 \mathrm{c}$ for detecting spatial and environmental novelty. Hippocampus 18:1064-1073.

Hunt DL, Linaro D, Si B, Romani S, Spruston N (2018) A novel pyramidal cell type promotes sharp-wave synchronization in the hippocampus. Nat Neurosci 21:985-995.

Ishizuka N, Cowan WM, Amaral DG (1995) A quantitative analysis of the dendritic organization of pyramidal cells in the rat hippocampus. J Comp Neurol 362:17-45.

Izhikevich EM, Desai NS, Walcott EC, Hoppensteadt FC (2003) Bursts as a unit of neural information: selective communication via resonance. Trends Neurosci 26:161-167.

Jaffe DB, Carnevale NT (1999) Passive normalization of synaptic integration influenced by dendritic architecture. J Neurophysiol 82:3268-3285.

Kaifosh P, Losonczy A (2016) Mnemonic functions for nonlinear dendritic integration in hippocampal pyramidal circuits. Neuron 90:622-634.

Klausberger T, Magill PJ, Márton LF, Roberts JD, Cobden PM, Buzsáki G, Somogyi P (2003) Brain-state- and cell-type-specific firing of hippocampal interneurons in vivo. Nature 421:844-848.

Knierim JJ, Neunuebel JP (2016) Tracking the flow of hippocampal computation: pattern separation, pattern completion, and attractor dynamics. Neurobiol Learn Mem 129:38-49.

Kohara K, Pignatelli M, Rivest AJ, Jung HY, Kitamura T, Suh J, Frank D, Kajikawa K, Mise N, Obata Y, Wickersham IR, Tonegawa S (2014) Cell type-specific genetic and optogenetic tools reveal hippocampal CA2 circuits. Nat Neurosci 17:269-279.

Kole MH (2011) First node of Ranvier facilitates high-frequency burst encoding. Neuron 71:671-682.

Kowalski J, Gan J, Jonas P, Pernía-Andrade AJ (2016) Intrinsic membrane properties determine hippocampal differential firing pattern in vivo in anesthetized rats. Hippocampus 26:668-682.

Krahe R, Gabbiani F (2004) Burst firing in sensory systems. Nat Rev Neurosci 5:13-23.

Krichmar JL, Nasuto SJ, Scorcioni R, Washington SD, Ascoli GA (2002) Effects of dendritic morphology on CA3 pyramidal cell electrophysiology: a simulation study. Brain Res 941:11-28.

Larkum ME, Zhu JJ, Sakmann B (1999) A new cellular mechanism for coupling inputs arriving at different cortical layers. Nature 398:338-341.

Lee D, Lin BJ, Lee AK (2012) Hippocampal place fields emerge upon singlecell manipulation of excitability during behavior. Science 337:849-853.

Lee H, Wang C, Deshmukh SS, Knierim JJ (2015) Neural population evidence of functional heterogeneity along the CA3 transverse axis: pattern completion versus pattern separation. Neuron 87:1093-1105.

Lein ES, Callaway EM, Albright TD, Gage FH (2005) Redefining the boundaries of the hippocampal CA2 subfield in the mouse using gene expression and 3-dimensional reconstruction. J Comp Neurol 485:1-10.

Leutgeb JK, Leutgeb S, Moser MB, Moser EI (2007) Pattern separation in the dentate gyrus and CA3 of the hippocampus. Science 315:961-966.

Li XG, Somogyi P, Ylinen A, Buzsáki G (1994) The hippocampal CA3 network: an in vivo intracellular labeling study. J Comp Neurol 339:181208.

Lisman J (1997) Bursts as a unit of neural information: making unreliable synapses reliable. Trends Neurosci 20:38-43.

London M, Häusser M (2005) Dendritic computation. Annu Rev Neurosci 28:503-532.

Lu L, Igarashi KM, Witter MP, Moser EI, Moser MB (2015) Topography of place maps along the CA3-to-CA2 axis of the hippocampus. Neuron 87:1078-1092.

Mankin EA, Diehl GW, Sparks FT, Leutgeb S, Leutgeb JK (2015) Hippocampal CA2 activity patterns change over time to a larger extent than between spatial contexts. Neuron 85:190-201. 
Marissal T, Bonifazi P, Aimé Picardo M, Nardou R, Franck Petit L, Baude A, Fishell GJ, Ben-Ari Y, Cossart R (2012) Pioneer glutamatergic cells develop into a morpho-functionally distinct population in the juvenile CA3 hippocampus. Nat Commun 3:1316.

Markus EJ, Barnes CA, McNaughton BL, Gladden VL, Skaggs WE (1994) Spatial information content and reliability of hippocampal CA1 neurons: effects of visual input. Hippocampus 4:410-421.

Meira T, Leroy F, Buss EW, Oliva A, Park J, Siegelbaum SA (2018) A hippocampal circuit linking dorsal CA2 to ventral CA1 critical for social memory dynamics. Nat Commun 9:4163.

Mizuseki K, Diba K, Pastalkova E, Buzsáki G (2011) Hippocampal CA1 pyramidal cells form functionally distinct sublayers. Nat Neurosci 14:11741181.

Nakamura NH, Flasbeck V, Maingret N, Kitsukawa T, Sauvage MM (2013) Proximodistal segregation of nonspatial information in CA3: preferential recruitment of a proximal CA3-distal CA1 network in nonspatial recognition memory. J Neurosci 33:11506-11514.

Neunuebel JP, Knierim JJ (2012) Spatial firing correlates of physiologically distinct cell types of the rat dentate gyrus. J Neurosci 32:3848-3858.

O'Keefe J (1976) Place units in the hippocampus of the freely moving rat. Exp Neurol 51:78-109.

O'Keefe J, Dostrovsky J (1971) The hippocampus as a spatial map: preliminary evidence from unit activity in the freely-moving rat. Brain Res 34:171-175.

Ognjanovski N, Schaeffer S, Wu J, Mofakham S, Maruyama D, Zochowski M, Aton SJ (2017) Parvalbumin-expressing interneurons coordinate hippocampal network dynamics required for memory consolidation. Nat Commun 8:16120.

Oliva A, Fernández-Ruiz A, Buzsáki G, Berényi A (2016) Spatial coding and physiological properties of hippocampal neurons in the cornu ammonis subregions. Hippocampus 26:1593-1607.

Pinault D (1994) Golgi-like labeling of a single neuron recorded extracellularly. Neurosci Lett 170:255-260.

Pinault D (1996) A novel single-cell staining procedure performed in vivo under electrophysiological control: morpho-functional features of juxtacellularly labeled thalamic cells and other central neurons with biocytin or neurobiotin. J Neurosci Methods 65:113-136.

Preston-Ferrer P, Coletta S, Frey M, Burgalossi A (2016) Anatomical organization of presubicular head-direction circuits. eLife 5:e14592.

Rama S, Zbili M, Fékété A, Tapia M, Benitez MJ, Boumedine N, Garrido JJ, Debanne D (2017) The role of axonal Kv1 channels in CA3 pyramidal cell excitability. Sci Rep 7:315.

Ranck JB (1973) Studies on neurons in dorsal hippocampal formation and septum in unrestrained rats: I. Behavioral correlates and firing repertoires. Exp Neurol 41:462-531.

Raus Balind S, Magó Á, Ahmadi M, Kis N, Varga-Németh Z, Lórincz A, Makara JK (2019) Diverse synaptic and dendritic mechanisms of complex spike burst generation in hippocampal CA3 pyramidal cells. Nat Commun 10:1859.

Ray S, Naumann R, Burgalossi A, Tang Q, Schmidt H, Brecht M (2014) Grid-layout and theta-modulation of layer 2 pyramidal neurons in medial entorhinal cortex. Science 343:891-896.

Rebola N, Carta M, Mulle C (2017) Operation and plasticity of hippocampal CA3 circuits: implications for memory encoding. Nat Rev Neurosci 18:208-220

Rich PD, Liaw HP, Lee AK (2014) Large environments reveal the statistical structure governing hippocampal representations. Science 345:814-817.

Rolls ET, Treves A (1994) Neural networks in the brain involved in memory and recall. Prog Brain Res 102:335-341.
Runyan CA, Sur M (2013) Response selectivity is correlated to dendritic structure in parvalbumin-expressing inhibitory neurons in visual cortex. J Neurosci 33:11724-11733.

San Antonio A, Liban K, Ikrar T, Tsyganovskiy E, Xu X (2014) Distinct physiological and developmental properties of hippocampal CA2 subfield revealed by using anti-Purkinje cell protein 4 (PCP4) immunostaining. J Comp Neurol 522:1333-1354.

Schaefer A, Collette F, Philippot P, Linden MV, der Laureys S, Delfiore G, Degueldre C, Maquet P, Luxen A, Salmon E (2003) Neural correlates of "hot" and "cold" emotional processing: a multilevel approach to the functional anatomy of emotion. Neuroimage 18:938-949.

Scharfman HE (1993) Spiny neurons of area CA3c in rat hippocampal slices have similar electrophysiological characteristics and synaptic responses despite morphological variation. Hippocampus 3:9-28.

Scharfman HE, Myers CE (2012) Hilar mossy cells of the dentate gyrus: a historical perspective. Front Neural Circuits 6:106.

Sik A, Penttonen M, Ylinen A, Buzsaki G (1995) Hippocampal CA1 interneurons: an in vivo intracellular labeling study. J Neurosci 15:6651-6665.

Stuart GJ, Spruston N (2015) Dendritic integration: 60 years of progress. Nat Neurosci 18:1713-1721.

Sun Q, Srinivas KV, Sotayo A, Siegelbaum SA (2014) Dendritic $\mathrm{Na}^{+}$spikes enable cortical input to drive action potential output from hippocampal CA2 pyramidal neurons. eLife 3:e04551.

Sun Q, Sotayo A, Cazzulino AS, Snyder AM, Denny CA, Siegelbaum SA (2017) Proximodistal heterogeneity of hippocampal CA3 pyramidal neuron intrinsic properties, connectivity, and reactivation during memory recall. Neuron 95:656-672.

Swanson LW, Hahn JD (2020) A qualitative solution with quantitative potential for the mouse hippocampal cortex flatmap problem. Proc Natl Acad Sci 117:3220-3231.

Takahashi H, Magee JC (2009) Pathway interactions and synaptic plasticity in the dendritic tuft regions of CA1 pyramidal neurons. Neuron 62:102111.

Tang Q, Brecht M, Burgalossi A (2014a) Juxtacellular recording and morphological identification of single neurons in freely moving rats. Nat Protoc 9:2369-2381.

Tang Q, Burgalossi A, Ebbesen C, Ray S, Naumann R, Schmidt H, Spicher D, Brecht M (2014b) Pyramidal and stellate cell specificity of grid and border representations in layer 2 of medial entorhinal cortex. Neuron 84:1191-1197.

Tang Q, Ebbesen CL, Sanguinetti-Scheck JI, Preston-Ferrer P, Gundlfinger A, Winterer J, Beed P, Ray S, Naumann R, Schmitz D, Brecht M, Burgalossi A (2015) Anatomical organization and spatiotemporal firing patterns of layer 3 neurons in the rat medial entorhinal cortex. J Neurosci 35:12346-12354.

Thome C, Kelly T, Yanez A, Schultz C, Engelhardt M, Cambridge SB, Both M, Draguhn A, Beck H, Egorov AV (2014) Axon-carrying dendrites convey privileged synaptic input in hippocampal neurons. Neuron 83:14181430.

Treves A, Rolls ET (1992) Computational constraints suggest the need for two distinct input systems to the hippocampal CA3 network. Hippocampus 2:189-199.

Vetter P, Roth A, Häusser M (2001) Propagation of action potentials in dendrites depends on dendritic morphology. J Neurophysiol 85:926-937.

Weaver CM, Wearne SL (2008) Neuronal firing sensitivity to morphologic and active membrane parameters. PLoS Comput Biol 4:e11.

Wittner L, Miles R (2007) Factors defining a pacemaker region for synchrony in the hippocampus. J Physiol 584:867-883.

Yartsev MM, Witter MP, Ulanovsky N (2011) Grid cells without theta oscillations in the entorhinal cortex of bats. Nature 479:103-107. 